\title{
DURACIÓN DE LA TELA TEJIDA COMO BARRERA MICROBIANA EN INSTRUMENTAL QUIRÚRGICO ESTERILIZADO POR CALOR HÚMEDO
}

Ana Isabel Pineda*, María Helena Vallejo**

\section{Resumen}

Introducción: la lona de tela tejida dril raza $100 \%$ algodón ha sido el material más utilizado para el embalaje de equipos e insumos medicoquirúrgicos esterilizados en calor húmedo, debido a la maniobrabilidad, menor posibilidad de rasgado que los papeles, empleo en equipos pesados y reutilización. Objetivo: describir el tiempo en el que la envoltura de doble lona de tela tejida actúa como una barrera antimicrobiana, manteniendo la esterilidad del instrumental quirúrgico hemostático mediante calor húmedo. Métodos: estudio descriptivo, serie de casos con quince paquetes embalados en tela tejida, que fueron sometidos a un ciclo de esterilización en calor húmedo, tomando 105 muestras de barrido para cultivo de las diferentes áreas de los paquetes en los días $0,5,10,15$ y 20 de almacenamiento. Resultados: no se evidenció crecimiento bacteriano secuencial en las capas de los paquetes estériles en los veinte días de almacenamiento. Hubo nueve cultivos positivos aislados sin relación con las otras áreas del paquete, atribuible a factores diferentes al mecanismo de barrera.

Palabras clave: esterilización, embalaje de equipos y suministros, textiles, barrera microbiana.

\section{DURATION OF THE MICROBIAL BARRIER PROVIDED BY A WOVEN COTTON WRAP OF SURGICAL INSTRUMENTS STERILIZED WITH MOIST HEAT}

\begin{abstract}
Introduction: $100 \%$ Pima cotton woven fabric has been the most commonly used wrapping material for medical surgical equipment and supplies sterilized with moist heat, due to its maneuverability, greater resistance to tearing than paper, usefulness for heavy equipment and reutilization. Objective: to describe for how long the double Pima cotton wrapping provides an antimocrobial barrier thus maintaining sterility of surgical instruments sterilized by means of moist heat. Methods: a descriptive study case series of 15 packages wrapped in woven material, which underwent a sterilization cycle with moist heat, collecting 105 screening culture samples from different areas of the packages on days $0,5,10,15$ and 20. Results: no sequential bacterial growth was evidenced on the layers of the sterilized packages along the 20 days of storage. Nine isolated cultures were positive but were unrelated with other areas of the package and were attributable to factors different to barrier mechanisms.
\end{abstract}

Key words: sterilization, equipment and supply packaging, textiles, microbial barrier.

Fecha recibido: enero 25 de 2012. Fecha aceptado: mayo 24 de 2012

* Instrumentadora Quirúrgica. Instructora Asociada. Fundación Universitaria de Ciencias de la Salud. Bogotá DC. Colombia.

** Docente de Instrumentació Quirúrgica. Instructora Asistente. Fundación Universitaria de Ciencias de la Salud. Bogotá DC. Colombia.
* Carlos Castro MD, Asesor Metodológico División de Investigaciones. InstructorAsociado. Fundación Universitaria de Ciencias de Salud. Bogotá DC. Colombia.

**iok Liceth Villamizar Gómez, Asesora Metodológica. División de Investigaciones. Profesora Asistente, Fundación Universitaria de Ciencias de la Salud. Bogotá DC. Colombia. 


\section{Introducción}

Los embalajes en la esterilización representan uno de los elementos más importantes dentro del proceso, debido a que gracias a estos se mantiene la condición de esterilidad en los paquetes durante el período de almacenamiento hasta la utilización del insumo medicoquirúrgico para el paciente. Por tanto, son de gran importancia en los programas de prevención de infecciones intrahospitalarias.

Con el advenimiento de nuevas tecnologías se han desarrollado materiales de embalaje que permiten que las condiciones de esterilidad se mantengan y además ofrecen beneficios como tiempo de almacenamiento más prolongado y que son descartables. La industria que desarrolla este tipo de insumos para la esterilización hospitalaria cuenta con múltiples estudios que los califica como una mejor opción frente a la lona de tela tejida. En la normatividad europea (EN) 13.795, se establece que para los materiales quirúrgicos de barrera se debe cumplir como requisito mínimo la impermeabilidad a líquidos, debido a que esta condición disminuye las infecciones quirúrgicas. ${ }^{1}$

En países en vía de desarrollo como Colombia se hace necesario tomar medidas en las cuales medie el costoefectividad, sin descuidar aspectos fundamentales como la seguridad del paciente. El Ministerio de la Protección Social a través del Manual de Buenas prácticas en Esterilización publicado en 2002, establece como parámetros necesarios para el material de embalaje: conservar la esterilidad hasta el momento de su uso, permitir la entrada del agente esterilizante, resistencia a la entrada de microorganismos, alta calidad debido a que se someten a temperaturas extremas y agentes químicos, capaz de resistir materiales pesados, no desprender partículas y resistencia al rasgado y al corte. ${ }^{2}$ Los requerimientos mencionados son acordes con muchas de las características de la tela tejida, pero es poco el soporte científico quc evidencie su efectividad. La Organización Panamericana de la Salud establece recomendaciones técnicas para este material mostrando que aún cuenta con vigencia: 100\% algodón, con una distribución de 55 hilos $/ \mathrm{cm}^{2}$, con urdimbre de 28 hilos $/ \mathrm{cm}^{2}$ y la trama de 27 hilos $/ \mathrm{cm}^{2}$, para te- ner un total de 140 hilos/pulgada ${ }^{2}$ en doble envoltura (lona primaria interna y otra secundaria externa). ${ }^{3}$

El tiempo de vigencia de esterilidad de un paquete es una de las variables de mayor controversia, pues algunos autores plantean que la fecha de caducidad depende del empaque y otros mencionan que el almacenamiento es el factor determinante, es decir no hay una estandarización. Por ejemplo la Association for the Advancement of Medial Instrumentation AAMI de los Estados Unidos, afirma que la vida de anaquel es el tiempo máximo que un paquete estéril puede estar almacenado y plantea que la designación del tiempo de esterilidad de los elementos médicos esterilizados es un suceso dependiente de las condiciones de almacenamiento y empaque.

La lona de tela tejida ha sido el material más utilizado para el embalaje de equipos e insumos medicoquirúrgicos que van a ser esterilizados en calor húmedo teniendo en cuenta su compatibilidad con este método, su maniobrabilidad, la posibilidad de rasgado es menor con respecto a los papeles de embalaje, se usa en equipos pesados y es reutilizable. Por lo tanto se considera un material vigente y se hace necesario contar con evidencia que de soporte a su utilización en las instituciones de salud. El presente estudio describe el tiempo en el que la envoltura de doble lona de tela tejida (dril 100\%) actúa como una barrera antimicrobiana, manteniendo la esterilidad del instrumental quirúrgico hemostático esterilizado en calor húmedo en una institución prestadora de servicios de salud de Bogotá DC.

\section{Métodos}

Se desarrolló un estudio descriptivo serie de casos, considerando la definición de caso como "la condición de esterilidad del paquete quirúrgico con envolturas e instrumental nuevos”. Los paquetes quirúrgicos fueron conformados por tres pinzas hemostáticas (Kelly) nuevas y el embalaje correspondió a dos lonas de tela tejida nuevas (drill 100\% algodón) de 30x30 cm las cuales hacen las veces de envoltura primaria y secundaria. Estas fueron sometidas a un proceso de lavado 
antes de su uso para evitar un sobrecalentamiento y un obstáculo para alcanzar la esterilización. El proceso se realiza con el fin de descontaminar las lonas de la suciedad visible y material biológico, y se busca abrir los poros de la tela para que permita la penetración del agente esterilizante al interior del paquete, tal como lo manifiestan Pinter y Gabrielloni en Brasil. ${ }^{5}$

Las 45 pinzas hemostáticas pasaron por un proceso de lavado y descontaminación con detergente enzimático de acuerdo con el protocolo de la institución, después fueron empacadas en grupos de tres en doble lona de tela tejida. En el interior del paquete se colocó un indicador químico clase IV (multiparámetro), se embaló con técnica de sobre cómo se muestra en la Figura 1 y se rotuló con indicador químico clase I.

Teniendo en cuenta que el esterilizador utilizado es un autoclave de vapor saturado bajo presión con bomba de vacío, se realizó un ciclo de validación con indicador químico clase II - test de Bowie Dick e indicador biológico clase III de lectura rápida, con el fin de establecer el buen funcionamiento del equipo, cuyos resultados fueron satisfactorios. Después este se cargó con los quince paquetes y se realizó ciclo de 45 minutos a una temperatura de $134^{\circ} \mathrm{C}$. Una vez terminado el proceso se llevaron a almacenamiento en un lugar exclusivo para evitar manipulación por parte del personal ajeno a la investigación.
Se asignó un número para cada paquete y en forma aleatoria se seleccionaron los que se abrirían los días $0,5,10,15$ y 20 para la toma de muestra de barrido de las áreas, como son envolturas externa cara interna, interna cara externa, interna cara interna, bisagras de la pinzas, cremalleras, orejas y estrías. Cada extendido se embaló en un tubo de ensayo con caldo Columbia como medio de preservación y en nevera portátil se trasladaron de inmediato al laboratorio de microbiología. La técnica de recolección de la muestra se describe en la Figura 2.

Las muestras fueron sembradas en agar $E M B$ y agar Columbia incubadas a $37^{\circ} \mathrm{C}$ durante 24 horas en el laboratorio de microbiología. El análisis de los datos se realizó en los programas de Microsoft Excel y Stata 10.1. Esta investigación fue aprobada por el comité de investigación de la Facultad de Instrumentación Quirúrgica de la Fundación Universitaria de Ciencias de la Salud, fue considerada sin riesgo de acuerdo con la resolución 8430 de 1993 y fue financiada por esta institución.

\section{Resultados}

El número total de muestras procesadas fue de 105 , las cuales se obtuvieron en siete áreas de quince paquetes quirúrgicos bajo observación. No se observó creci-

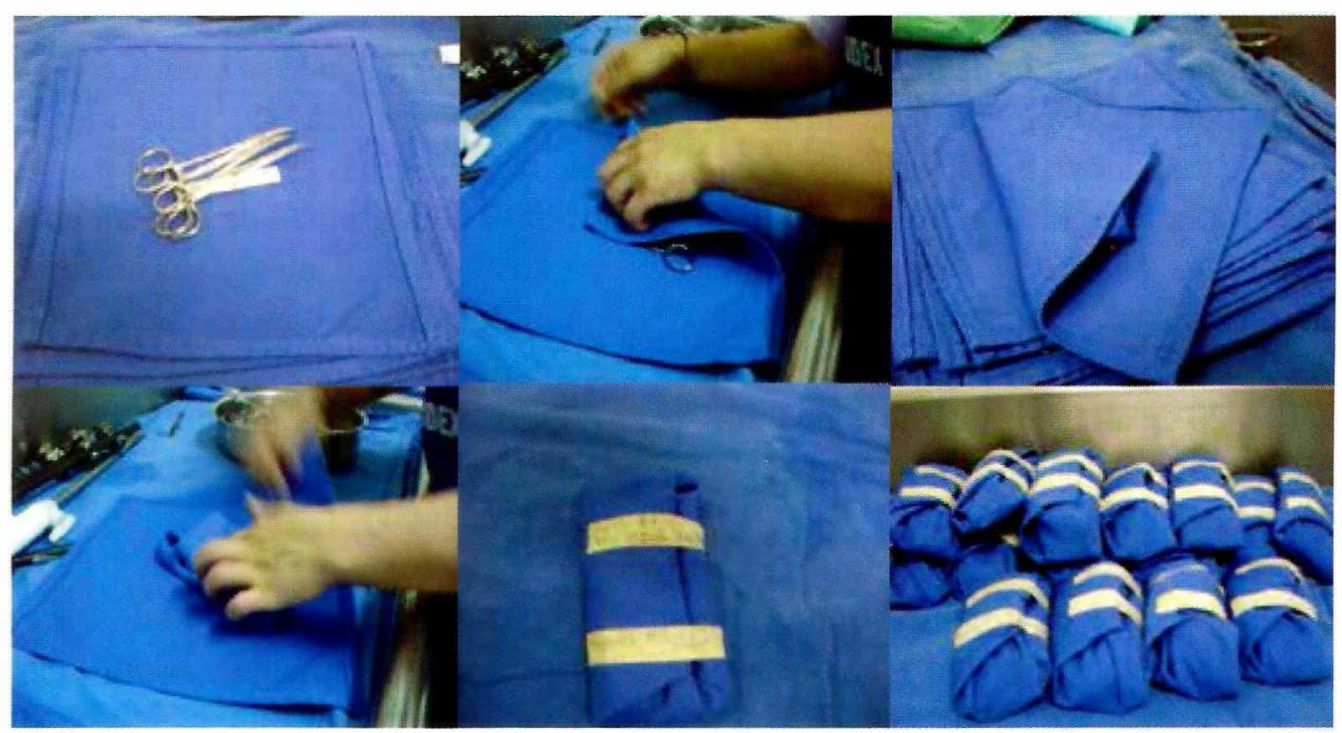

Figura I. Embalaje con técnica de sobre (fuente: los autores). 
Total de muestras

recolectadas por paquete

7. Se repiten los mismos

pasos para los otros dos

paquetes. En total 21

muestras por día

\section{Toma de muestra de las estrias delas pinzas \\ Toma de muestra de orejas delas pinzas}

Toma de muestra de bisagras delas pinzas

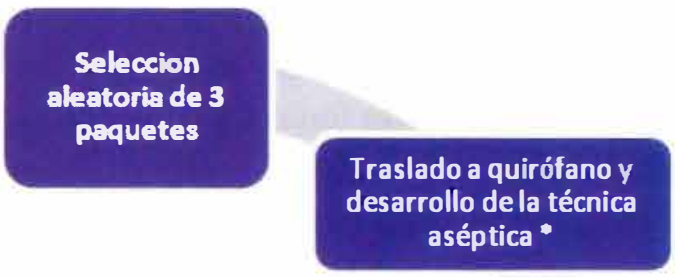

Apertura de paquete y toma de la muestra dela envoltura externa cara in terna y se embala para traslado en tubo de ensayo (igual para todas las muestras)

Toma de muestra de envoltura interna cara externa

Toma de muestra de cremalleras de las pinzas

Figura. 2. Técnica de recolección de las muestras de barrido de las áreas del paquete estéril. *Se entiende por técnica aséptica a: I.Lavado de manos quirúrgico. 2.Apertura de paquete de ropa. 3. Postura de bata y guantes estériles. 4. Circulación de insumos para la toma de muestras a la mesa. 5. Apertura del primer paquete.

miento bacteriano en las diferentes áreas del paquete en los días $0,5,10,15$ y 20 de almacenamiento. Se obtuvieron nueve cultivos positivos de manera aislada, los cuales uno corresponde a Staphylococcus aureus en la envoltura externa cara interna, tres a Staphylococcus epidermis, en las orejas, bisagras y cremalleras de las pinzas, cinco a Bacillus esporulados en la envoltura interna cara interna, estrías, orejas y cremalleras de las pinzas. Los cultivos positivos se presentaron en los días de 0, 5, 10 y 20 de almacenamiento siendo los días 0 y 20 los de mayor frecuencia de contaminación, como se muestra en la Tabla 1.

En los veinte días de almacenamiento (tiempo de observación) no se presentó crecimiento bacteriano secuencial en las envolturas de los paquetes del estudio, se obtuvieron dos muestras aisladas con cultivos positi- vos, la primera corresponde a la envoltura externa cara interna tomada el mismo día de la esterilización del paquete (día 0) donde se identificó un Staphylococcus aureus y un Bacillus sp., sin evidencia del mismo en las envolturas más externas del paquete. Los cultivos positivos se presentan de manera aislada sin relación con áreas circundantes y sin incremento de acuerdo con el número de días en que estuvo almacenado el paquete (Figura 3).

\section{Discusión}

En la actualidad en las centrales de esterilización de las instituciones de salud la lona de tela tejida se utiliza con frecuencia como elemento de embalaje en la esterilización con vapor saturado bajo presión, debido 
Tabla I. Microorganismos aislados según día del cultivo y paquete de origen

\begin{tabular}{|c|c|c|c|c|c|c|}
\hline \multirow[b]{2}{*}{ Dia } & \multirow{2}{*}{$\begin{array}{l}\text { Paquete } \\
\text { Número }\end{array}$} & \multirow{2}{*}{$\begin{array}{l}\mathbf{N}^{\circ} \text { de } \\
\text { muestras }\end{array}$} & \multicolumn{4}{|c|}{ Microorganismos } \\
\hline & & & Bacillus sp. & S. aureus & S. epidermidis & Tota \\
\hline \multirow{3}{*}{0} & 2 & 7 & 0 & 1 & 1 & 2 \\
\hline & 4 & 7 & 0 & 0 & 0 & 0 \\
\hline & 7 & 7 & 2 & 0 & 0 & 2 \\
\hline \multirow{3}{*}{5} & 6 & 7 & 0 & 0 & 1 & 1 \\
\hline & 8 & 7 & 0 & 0 & 0 & 0 \\
\hline & 13 & 7 & 0 & 0 & 0 & 0 \\
\hline \multirow{3}{*}{10} & 5 & 7 & 1 & 0 & 0 & 1 \\
\hline & 12 & 7 & 0 & 0 & 0 & 0 \\
\hline & 15 & 7 & 0 & 0 & 0 & 0 \\
\hline \multirow{3}{*}{15} & 1 & 7 & 0 & 0 & 0 & 0 \\
\hline & 10 & 7 & 0 & 0 & 0 & 0 \\
\hline & 11 & 7 & 0 & 0 & 0 & 0 \\
\hline \multirow{3}{*}{20} & 3 & 7 & 1 & 0 & 1 & 2 \\
\hline & 9 & 7 & 0 & 0 & 0 & 0 \\
\hline & 14 & 7 & 1 & 0 & 0 & 1 \\
\hline Total & 15 & 105 & 5 & I & 3 & 9 \\
\hline
\end{tabular}

\section{Microorganismo}

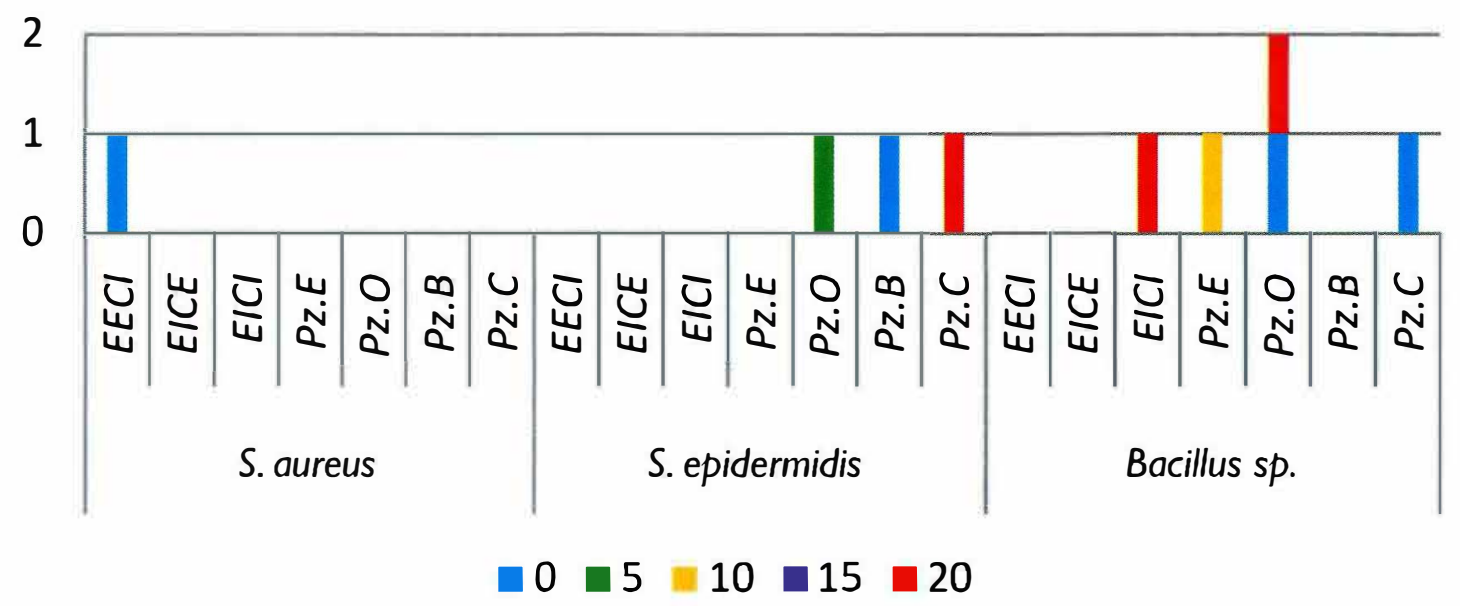

Figura 3. Resultados de los cultivos por día, área de toma y tipo de microorganismos. *EECl: envoltura externa cara interna; EICE: envoltura interna cara externa; EICl: envoltura interna cara interna; Pz.E: pinza estrías; Pz. O: pinza orejas; Pz. B: pinza bisagras; Pz. C: pinza cremalleras. 
a su compatibilidad y a las características del material, ofreciendo múltiples beneficios a pesar de tantos debates que surgen frente a los materiales descartables. Robles plantea que los textiles se mantienen vigentes gracias a su bajo costo, a que no causan efecto perjudicial sobre los elementos que contienen y brinda protección adecuada contra influencias externas y contaminaciones potenciales hasta el momento de la apertura del paquete. ${ }^{6}$

Por otra parte la norma europea (EN) 13795, de junio 2006 del CEN (Comité Europeo de Normalización), establece que los materiales reutilizables de algodón o mezclas de este y poliéster no constituyen una barrera segura contra los gérmenes basándose en las características del textil como su capilaridad, en donde sus fibras de algodón son absorbentes, no impermeables y las capas superpuestas de algodón pueden incluso intensificar el paso de fluidos; menciona que el tamaño del poro en el tejido de algodón es mínimo de 80 micrómetros en relación con el tamaño de las bacterias que es de aproximadamente un micrómetro y aunque se utilicen múltiples capas de tejido de algodón, este no ofrece una resistencia segura a la penetración microbiana, en especial en condiciones húmedas. Debido a los múltiples reprocesamientos del textil ocurre ruptura de fibras y permite un desprendimiento de partículas. La variable tiempo de almacenamiento para elementos procesados por esterilización cuenta con poca evidencia. Algunos autores como Zanon ${ }^{7}$ sustenta que el almacenamiento para productos estériles embalados en textil debe ser de tres semanas en vitrinas abiertas y ocho en las cerradas, y Brito $^{8}$ menciona que estos elementos permanecen estériles por 90 días en condiciones adecuadas de almacenamiento.

Es por ello que en el presente estudió se vigiló si había crecimiento bacteriano de tal manera que se viera afectado el mecanismo de barrera de la doble lona de tela tejida en función del tiempo. El período de almacenamiento máximo establecido por la institución donde se desarrolló el estudio fue de quince días y se adicionaron cinco días más para la observación.

Frente a los resultados positivos de los cultivos, se puede decir que el Staphylococcus aureus es un mi- croorganismo que hace parte de la flora normal de la piel y mucosas, encontrándose en el $40 \%$ de las personas sanas y está presente en el ambiente hospitalario. Al ser sometido a un proceso de esterilización a altas temperaturas es eliminado por completo gracias al mecanismo de acción del vapor saturado bajo presión, el cual consiste en la desnaturalización de proteínas de los microorganismos, logrando así su muerte celular"; su presencia se puede asociar con una posible ruptura de la técnica aséptica y contaminación del escobillón estéril en el proceso de la recolección de la muestra. Los Bacillus sp., representan un verdadero reto para la esterilización, siendo la eliminación de estos el principal objetivo de este proceso, lo que hace evidente una incongruencia con los indicadores biológicos lo cual puede representar una falla en el equipo de esterilización y en la validación del mismo, pero no se atribuye a crecimiento bacteriano posterior a la esterilización debido a que los microorganismos esporulados no cuentan con la capacidad de replicación, por lo tanto este se encontraba desde antes de su esterilización.

Los cultivos positivos de áreas del interior del paquete corresponden a Staphylococcus aureus, Staphylococcus epidermis y Bacillus sp., lo cual se puede explicar con las mismos argumentos expuestos antes.

\section{Conclusiones}

A partir de los resultados y al no evidenciarse crecimiento bacteriano secuencial en las capas de los paquetes estériles, puede sugerirse que el mecanismo de barrera microbiana de la lona de tela tejida se mantiene en veinte días de almacenamiento.

Los cultivos positivos se asociaron con fuentes de contaminación en el proceso de recolección de la muestra y a dificultades propias del equipo de esterilización donde se procesaron los paquetes. Se plantea la necesidad de realizar estudios que ofrezcan soporte científico de la efectividad de la barrera antimicrobiana de la lona de tela tejida, de tal manera que se respalde su uso con el empleo de calor húmedo en las centrales de esterilización hospitalaria, pues no se pueden desconocer las ventajas que ofrecen los textiles frente a los materiales desechables al ser reutilizables y no 


\section{generar impacto ambiental, en comparación con estos últimos que cuentan con tiempos de degradabilidad muy prolongados y pueden ocasionar graves daños al medio ambiente a largo plazo.}

\section{Referencias}

1. Vankaekenbergh V, WillièmeO.. Surgical drapes, gowns and clean air suits, used as medical devices for patients, clinical staff and equipment . One year of experience with EN 13795-3... the perspective of the user. 5th Congress Of Eornac; 2009 April 17-19, Copenhagen : European Committee for Standardization.

2. Colombia. Ministerio de Protección Social. Resolución 02183 de 2004 por la cual por la cual se adopta el Manual de Buenas Prácticas de Esterilización para Prestadores de Servicios de Salud. Diario Oficial, 45.611 (Jul. 9 2004).

3. Organización Panamericana de la Salud. Manual de esterilización para centros de salud. Washington D.C: OPS; 2008.
4. American National Standard, Association for the Advancement of Medical Instrumentation. Processing of reusable surgical textiles for use in health care facilities (ANSI/AAMI ST 65:2000). Arlington, VA: AAMI; 2000.

5. Pinter M.G, Gabriellone M.C. Central de material e esterilizaçao. In: Fernandes A, et al. Infecçao Hospitalar e suas interfaces na área da saúde. Sao Paulo: Atheeneu, 2000. p. $1041-1060$

6. Robles, C. Tipos de Empaques para Materiales quirúrgicos prevención de infecciones. Medwave.[Revista en internet]. 2004 Sep [citado 22 Jun 2012]; 4(8): [aprox. 3 p.] [consultado 2011 Ene 20]. Disponible en: http://www.mednet.cl/ link.cgi/Medwave/Enfermeria/InstrumentistasACS2003/septiembre2004/2676.

7. Zanòn U, Neves J. Infeç̧oes Hospitalares: Prevençao, Diagnóstico e Tratamento. Rio de Janeiro: Medsi, 1987.

8. Brito M. Galvao C, Françolin L, Rotta C. Validation of the sterilization process of medical and hospital devices according to different packaging types. (Idioma original: Portugués). Rev. Bras. Enferm. 2002; 55(4): 414-19.

9. Murray P, Rosenthal K, Pfaller M. Microbiología Médica. Sa ed. Madrid, Espaกีa: ElsevierMosby; 2006. 